\title{
Long-term outcome of symptomatic severe ostial vertebral artery stenosis (OVAS)
}

\author{
Alexander Karameshev • Gerhard Schroth • \\ Pasquale Mordasini • Jan Gralla • Caspar Brekenfeld • \\ Marcel Arnold • Marie-Luise Mono • \\ Heinrich P. Mattle • Do-Dai Do • Krassen Nedeltchev
}

Received: 2 October 2009 / Accepted: 12 January 2010/Published online: 11 February 2010

(C) Springer-Verlag 2010

\begin{abstract}
Introduction The optimal management of patients with symptomatic severe ostial vertebral artery stenosis (OVAS) is currently unclear. We analyzed the long-term outcome of consecutive patients with OVAS who received either medical treatment (MT) or vertebral artery stenting (VAS). Methods Thirty-nine ( $>70 \%$ ) patients with severe OVAS were followed for a mean period of 2.8 years. The decision for VAS $(n=10)$ or MT $(n=29)$ was left to the clinician. The Kaplan-Meier method was used to assess the risk of recurrent stroke, transient ischemic attack (TIA), or death over the study period.

Results Patients in the VAS group were significantly younger and more likely to have bilateral VA disease ( $P=0.04$ and $P=0.02$ ). VAS was successfully performed in
\end{abstract}

A. Karameshev $\cdot$ G. Schroth $(\varangle) \cdot$ P. Mordasini $\cdot$ J. Gralla $\cdot$

C. Brekenfeld

Institute of Diagnostic and Interventional Neuroradiology, Inselspital, University of Bern,

3010 Bern, Switzerland

e-mail: gerhard.schroth@insel.ch

A. Karameshev $\cdot$ M. Arnold $\cdot$ M.-L. Mono $\cdot$ H. Mattle $\cdot$

K. Nedeltchev

Neurology, University of Bern,

Bern, Switzerland

D.-D. Do

Angiology, University of Bern,

Bern, Switzerland

\section{A. Karameshev}

Department of Neurology, Medical University of Sofia,

Sofia, Bulgaria

K. Nedeltchev

Department of Neurology, Triemli Hospital,

Zurich, Switzerland all ten patients. The periprocedural risk within 30 days was $10 \%$ (one TIA). The overall restenosis rate was $10 \%$. One restenosis occurred after 9 months in a patient treated with bare-metal stent. At 4 years of follow-up, VAS showed a nonsignificant trend toward a lower risk for the combined endpoint of TIA and stroke in posterior circulation compared to medical treatment ( $10 \%$ vs. $45 \%, P=0.095$; relative risk $(\mathrm{RR})=0.24,95 \%$ confidence interval $(\mathrm{CI})$ 0.031-1.85). Patients with bilateral VA disease had a significantly lower recurrence risk after VAS compared with medical treatment $(0 \%$ vs. $91 \%$ at 4 years, $P=0.004$; RR $0.10,95 \%$ CI $0.022-0.49$ )

Conclusion VAS was performed without permanent complications in this small series of patients with symptomatic severe OVAS. The long-term benefit seems to be confined to patients with bilateral but not to those with unilateral VA disease.

Keywords Ostial vertebral artery stenosis · Stenting · Angioplasty $\cdot$ Secondary prevention $\cdot$ Long term

Posterior circulation strokes (PCS) account for approximately $25 \%$ of all ischemic strokes $[1,2]$. In $20-25 \%$ of the PCS, conventional or magnetic resonance angiography (MRA) reveals a severe ostial stenosis or occlusion of the vertebral artery (VA) [3, 4]. Occlusive disease involving the ostium of the VA can cause a PCS by either hemodynamic compromise or arterio-arterial embolism [5, 6].

Secondary prevention aims to improve the hemodynamic situation and to eliminate the possible source of thromboembolism. Preventive measures include medical treatment (MT) and surgical or endovascular revascularization. MT consists of antiplatelets, statins, and a thorough control of the blood pressure in order to avoid hypotension. Because of the difficult access to the VA origin, surgery is rarely 
performed in the clinical routine. Endovascular therapy is less invasive and thus a promising alternative to surgery. However, its long-term benefits compared with MT are currently uncertain.

The only randomized trial comparing endovascular with MT is the Carotid and Vertebral Artery Transluminal Angioplasty Study (CAVATAS) [7]. The study failed to show a benefit of endovascular treatment, but the number of included patients was small $(n=16)$. A larger randomized trial, the Vertebral Artery Stenting Trial, has recently been launched, though the results are not to be awaited soon [8].

The present study analyzed the long-term outcome of consecutive patients with symptomatic ostial vertebral artery stenosis (OVAS), who were admitted to a single stroke center over a period of 10 years and received either MT or vertebral artery stenting (VAS).

\section{Methods}

\section{Patient selection}

From January 2000 to July 2008, 39 consecutive patients with a recently symptomatic (within $48 \mathrm{~h}$ ) severe $(>70 \%)$ OVAS were admitted to a single university-based stroke center. Demographic data, vascular risk factors, National Institutes of Health Stroke Scale (NIHSS) score [9] on admission, and stroke etiology according to the Trial of Org 10172 in Acute Stroke Treatment criteria [10] were assessed prospectively by stroke neurologists. Data were entered into a computer-based databank. The following stroke risk factors were assessed: age, sex, hypertension (defined by preadmission history and medical records), diabetes mellitus (defined by venous plasma glucose concentration of $\geq 7.0 \mathrm{mmol} / \mathrm{l}$ after an overnight fast on at least two separate occasions and/or $\geq 11.1 \mathrm{mmol} / 12$ hours after the ingestion of $75 \mathrm{~g}$ of oral glucose and on one other occasion during the 2-h test), current cigarette smoking, hypercholesterolemia (plasma cholesterol concentration $>5 \mathrm{mmol} / \mathrm{l}$ ), decreased plasma high-density lipoprotein (level $<1 \mathrm{mmol} / \mathrm{l}$ ), increased plasma low-density lipoprotein (level $>3 \mathrm{mmol} / \mathrm{l}$ ), increased plasma triglycerides (level $>1.6 \mathrm{mmol} / \mathrm{l}$ ), coronary artery disease, and peripheral artery disease.

The patients had suffered either an acute PCS $(n=18)$ or a transient ischemic attack (TIA; $n=21$ ) in the posterior circulation. There were no alternative causes of stroke (e.g., cardiac sources of embolism, small artery disease, and other determined stroke etiologies).

The diagnosis of PCS was based on the sudden onset of focal neurological deficits from the vertebrobasilar territory lasting for more than $24 \mathrm{~h}$ with corresponding findings on brain imaging. Posterior circulation TIAs were assumed if symptoms from the vertebrobasilar territory recovered completely within $24 \mathrm{~h}$. Brain imaging involved nonenhanced computed tomography (CT) in 23 patients and multimodal MRI (axial T1-, T2-, and intermediate-weighted images, diffusion-weighted images, perfusion-weighted images) in 30 patients (both imaging modalities were performed in 14 patients). The diagnosis of proximal vertebral artery stenosis was established by color-coded duplex ultrasonography in all patients and verified by $\mathrm{CT}$ angiography (CTA) in ten, contrast-enhanced MRA in 25 , or digital subtraction angiography (DSA) in 20 patients. The DSA was not preceded by CT or MR angiography in four patients.

A hemodynamically significant ostial stenosis was suspected if color-coded duplex ultrasonography revealed peak systolic velocities $>100 \mathrm{~cm} / \mathrm{s}$ at the origin of the vertebral artery and an antegrade blood flow in the more distal segments of the vessel [11]. CTA, MRA, and DSA used the following formula to define the degree of stenosis: $(1-A / V) \times 100(\%)$, where $A$ was the diameter of the residual lumen at the point of maximal stenosis and $V$ the diameter of the distal disease-free vertebral artery. This method is similar to the one used to measure carotid artery stenosis in the North American Symptomatic Carotid Endarterectomy Trial [12]. The CTA or MRA axial source images were used to define the diameter of the residual lumen. The image analysis was performed by a neurologist (A.K.) and an interventional neuroradiologist (G.S.) in consensus.

\section{Treatment}

The decision to treat patients medically $(n=29)$ or by VAS $(n=10)$ was left to the discretion of the treating physician. Reasons to perform VAS were: (1) intra-arterial thrombolysis in two patients with a basilar artery thrombosis due to an ostial occlusion or pseudo-occlusion of the dominant vertebral artery in order to ensure the endovascular access to the basilar artery [13]; (2) crescendo TIAs in patients under MT $(n=3)$; (3) hemodynamic TIA or PCS, in which symptoms had occurred most likely because of arterial hypotension $(n=5)$. All patients undergoing VAS had no limiting comorbidities and an estimated life expectancy greater than 5 years.

\section{Medical treatment}

MT included aspirin $100-00 \mathrm{mg} /$ day $(n=20)$, clopidogrel $75 \mathrm{mg} /$ day $(n=1)$, vitamin $\mathrm{K}$ antagonists $(n=5)$, and the combination of aspirin and clopidogrel $(n=3)$. In addition, 20 patients were on statins $(n=20)$, and 18 patients were given antihypertensive drugs $(n=18)$.

\section{Vertebral artery stenting}

Twelve VAS procedures were performed in ten patients to treat 11 vertebral arteries with origin stenosis. 
All patients undergoing VAS received aspirin $100 \mathrm{mg}$ and clopidogrel $75 \mathrm{mg}$. Dual antiplatelet therapy was continued for 12 months, and aspirin was continued indefinitely.

Vascular access was gained through a femoral approach. A 7- or an 8-F-long sheath or an arrow sheath was placed in the proximal subclavian artery. An 8-F balloon catheter was used if proximal protection of embolic events by reversed flow was intended. The target ostial VA stenosis was passed with microwire or a FilterWire if distal protection was used. Using biplane roadmap, the balloon-expandable stent was positioned across the stenosis over the 0.014-in. wire with the proximal end of the stent placed in the subclavian artery. At the origin of the vertebral artery, predilatation was not performed. In one patient with a bilateral internal carotid occlusion and a high-grade left vertebral artery stenosis, right brachial access with a 5-F sheath was used for the treatment of a symptomatic high-grade right vertebral artery stenosis. The following drug-eluting $(n=7)$ and bare-metal $(n=5)$ stents were used: Endeavor RX (Medtronic Inc., Minneapolis, MN, USA) in six cases, Taxus Express2 (Boston Scientific, Natick, MA, USA) in one case, Herculink (Abbott Laboratories, Abbott Park, IL, USA) in three cases, Titan-2-BAS (Hexacath, RueilMalmaison, France) in one case, and Tetra-Megalink (Guidant, Indianapolis, IN, USA) in one case. Two patients received two stents each - in one patient, a restenting procedure was needed because of restenosis after 9 months. The restenosis was treated with a drug-eluting stent (DES) in the bare-metal stent. In the other patient, both vertebral arteries were treated.

\section{Clinical endpoints}

The primary efficacy endpoint was the freedom from TIA and fatal and nonfatal PCS during the follow-up.

The primary safety endpoint was the solitary rate of all-cause death, stroke-related death, any stroke including hemorrhagic stroke and stroke in the anterior circulation, myocardial infarction (MI), and any reintervention up to 30 days after the index event.

Secondary endpoints were the rates of any stroke (including hemorrhagic and contralateral stroke), TIA, transient retinal ischemia (amaurosis fugax), retinal infarction, in-stent stenosis, repeated target vessel revascularization, all-cause death, and stroke-related death during the follow-up.

Procedural success

The procedural success was defined as: (1) achievement of residual stenosis $<30 \%$ and (2) absence of adverse events during the hospital stay or within $24 \mathrm{~h}$ of the index procedure.
Methods of clinical and radiological follow-up

The medically treated patients were followed annually on a scheduled basis. All patients underwent a clinical examination and a color-coded duplex ultrasound. Clinical endpoint events and medication were documented.

Patients who underwent VAS were followed at 30 days, at 6 months, at 12 months after treatment, and annually afterwards. All patients underwent a clinical examination and a color-coded duplex ultrasound. Patients with ultrasound findings suggesting in-stent stenosis underwent further workup by CTA, MRA, and/or DSA. The MRA has been demonstrated to overestimate the stenosis grade of the VA origin in about $15 \%$ of the cases [14]. In our study, MRA and CTA were used generally to confirm the findings of the color-coded duplex ultrasonography. The latter has considerably higher accuracy in proximal vertebral artery stenosis quantification, with specificity up to $99 \%$ for stenoses greater than $70 \%$ [15]. In-stent stenosis was defined as the presence of $<50 \%$ stenosis immediately after treatment, with an increase of stenosis to $>50 \%$ during follow-up.

If a patient developed new neurological symptoms during the follow-up, she/he was managed according to current guidelines for acute stroke treatment. The decision to perform CT or MR brain imaging was guided by the patients' clinical condition and the time elapsed from the symptom onset.

\section{Statistical methods}

Data are reported in frequency tables. Quantitative data are expressed as mean values $\pm 1 \mathrm{SD}$. The NIHSS score for each patient at admission is given as a median value. Differences between groups and the effect of patient characteristics on clinical and radiological endpoints were assessed using Fisher's exact test (for comparison of proportions), Student $t$ test (for comparison of continuous variables), and MannWhitney $U$ test (for comparison of ordinal variables). The Kaplan-Meier method was used to determine the likelihood of freedom from fatal and nonfatal PCS during follow-up. The log-rank test was used to compare the cumulative incidence curves between the treatment groups. Predictors of recurrent events according to treatment assignment were analyzed by a Cox proportional hazards model. Two-sided $P$ values less than 0.05 were considered statistically significant.

\section{Results}

Baseline clinical and radiologic characteristics

The baseline clinical and radiologic characteristics of all patients $(n=39)$ are given in Table 1 . Twenty-nine patients 
Table 1 Baseline clinical and radiologic characteristics.

\begin{tabular}{lcll}
\hline Characteristics & $\begin{array}{l}\text { Medical } \\
\text { treatment }(n=29)\end{array}$ & $\begin{array}{l}\text { Vertebral artery } \\
\text { stenting }(n=10)\end{array}$ & $P$ value \\
\hline Female, $n(\%)$ & $12(41)$ & $2(20)$ & 0.22 \\
Age, year (SD) & $68(8)$ & $60(13)$ & 0.04 \\
Follow-up, year (SD) & $3.1(2.7)$ & $2.1(1.5)$ & 0.27 \\
Index event, $n$ (\%) & $22(76)$ & $5(50)$ & 0.12 \\
TIA & $7(24)$ & $5(50)$ & 0.12 \\
PCS & $1(0.45)$ & $3.5(3.6)$ & 0.03 \\
NIHSS on admission, median (SEM) & & & \\
Vascular risk factors, $n$ (\%) & $17(59)$ & $7(70)$ & 0.52 \\
Hypertension & $7(24)$ & $2(20)$ & 0.79 \\
Diabetes mellitus & $3(10)$ & $6(60)$ & 0.001 \\
Current smoker & $20(69)$ & $7(70)$ & 0.95 \\
Hypercholesterolemia & $5(17)$ & 0 & 0.16 \\
Coronary artery disease & $1(3)$ & 0 & 0.55 \\
Peripheral artery disease & $11(38)$ & $8(80)$ & 0.02 \\
Occlusive disease of the contralateral VA & &
\end{tabular}

received medical treatment only (medical group), and ten patients underwent VAS (VAS group). Patients of the medical group were older, had less severe neurological deficits on admission, and were less often current smokers. Both groups did not differ in terms of sex, type of the index event (TIA or PCS), or vascular risk factors (except for current cigarette smoking). There were significantly more patients with occlusive disease of the contralateral vertebral artery in the VAS group than in the medical group $(P=0.02)$.

Primary safety endpoint (30-days follow-up)

VAS was performed within 0 to 2 days after the index event. In the medical group, one patient died from basilar artery thrombosis 22 days after the index event. In the VAS group, a TIA occurred 1 day after the procedure. There were no hemorrhagic strokes, strokes in the anterior circulation, MI, or reinterventions within 30 days after the index event.

Primary efficacy endpoint (long-term follow-up)

Outcome events during a mean follow-up of 2.8 years are summarized in Table 2. Two fatal PCS, one nonfatal PCS, and ten TIAs were observed in the medical group, compared with one TIA in the stented group. In the medical group, eight TIA and three strokes occurred in patients with acetylsalicylic acid, one TIA with clopidogrel and one TIA with oral anticoagulation.

At 4 years of follow-up, VAS showed a nonsignificant trend toward a lower risk in the combined endpoint of TIA and nonfatal and fatal PCS (10\% vs. $45 \%, P=0.095$; relative risk $(\mathrm{RR})=0.24,95 \%$ confidence interval $(\mathrm{CI}) 0.031-1.85)$, when compared to medical treatment (Fig. 1).

Table 2 Primary efficacy and secondary endpoints.

\begin{tabular}{|c|c|c|c|c|c|c|}
\hline & \multicolumn{2}{|l|}{ Events } & \multicolumn{2}{|c|}{ Probability of event at 4 years } & \multirow[t]{2}{*}{ HR $(95 \% \mathrm{CI})$} & \multirow[t]{2}{*}{$P$ value } \\
\hline & Stenting & Medical & Stenting & Medical & & \\
\hline Primary efficacy endpoints & 1 & 13 & $10 \%$ & $44.8 \%$ & $0.24(0.03-1.88)$ & 0.14 \\
\hline TIA & 1 & 10 & $10 \%$ & $34.48 \%$ & $0.32(0.04-2.55)$ & 0.26 \\
\hline Fatal PCS & 0 & 1 & $0 \%$ & $3.44 \%$ & $0.0(0.0-10 \mathrm{E} 12)$ & 0.56 \\
\hline Nonfatal PCS & 0 & 2 & $0 \%$ & $6.89 \%$ & $0.0(0.0-10 \mathrm{E} 12)$ & 0.42 \\
\hline Secondary endpoints & 1 & 4 & $10 \%$ & $13.79 \%$ & $1.86(0.18-18.76)$ & 0.60 \\
\hline Hemorrhagic stroke & 0 & 1 & $0 \%$ & $3.44 \%$ & $0.0(0.0-10 \mathrm{E} 12)$ & 0.67 \\
\hline Any death & 0 & 3 & $0 \%$ & $10.34 \%$ & $0.0(0.0-10 \mathrm{E} 12)$ & 0.51 \\
\hline Anterior circulation stroke & 0 & 1 & $0 \%$ & $3.44 \%$ & $0.0(0.0-10 \mathrm{E} 12)$ & 1 \\
\hline Restenosis & 1 & - & $10 \%$ & - & - & - \\
\hline
\end{tabular}




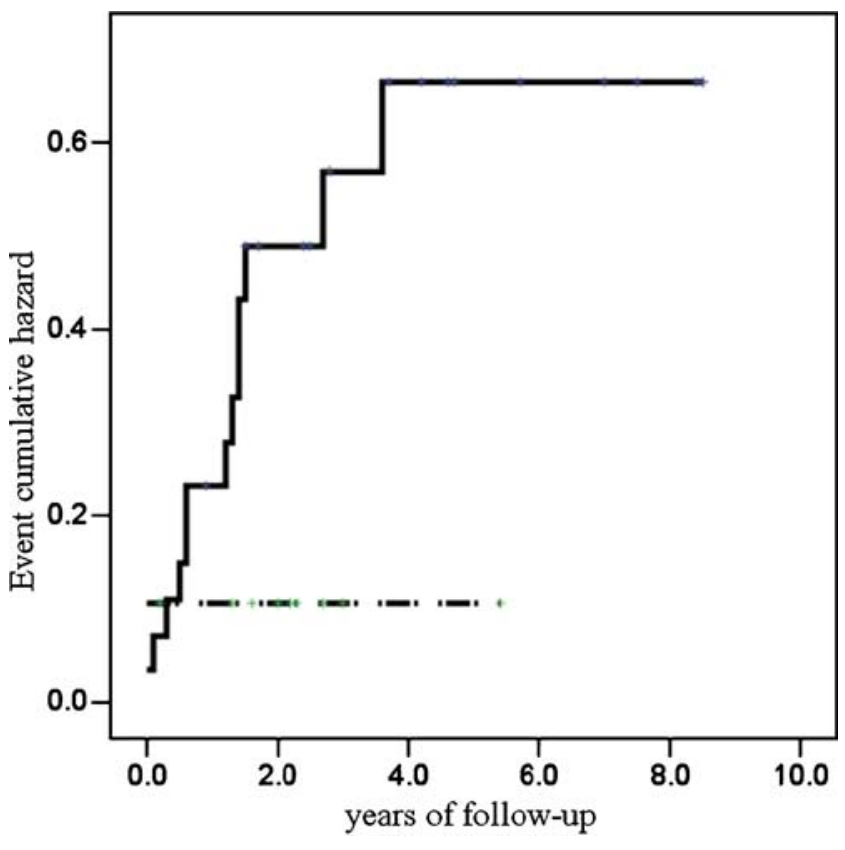

Fig. 1 Probability of TIA and fatal and nonfatal stroke stratified for medical treatment (continuous line) and VAS (dashed line)

Cox regression analysis was used to assess for predictors of recurrent PCS or TIA (Fig. 2). Sex, age $>70$ years, vascular risk factors (except for hypertension), and stroke or TIA as an index event did not influence the outcome, neither in the medical nor in the stented group. Patients with occlusive disease of the contralateral vertebral artery had a significantly lower risk of recurrent PCS or TIA after VAS compared with

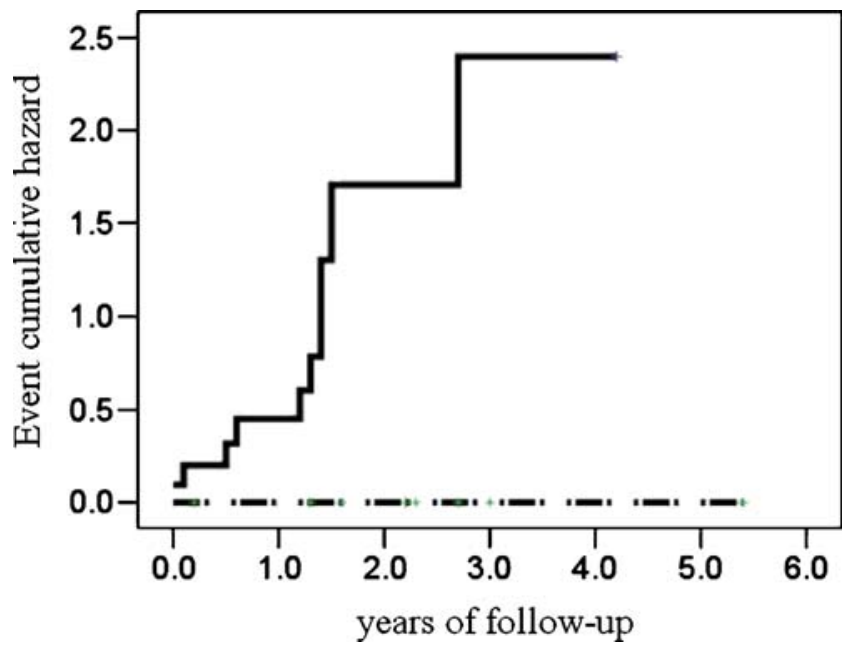

Fig. 3 Probability of recurrent TIA or PCS stratified for medical treatment (continuous line) and VAS (dashed line) in the subgroup of patients with occlusive disease of the contralateral vertebral artery

medical treatment ( $0 \%$ vs. $91 \%$ at 4 years, $P=0.004$; RR $0.10,95 \%$ CI $0.022-0.49$ Figs. 2 and 3). The risk of recurrent PCS or TIA in patients with hypertension was significantly higher after VAS than with medical treatment ( $57 \%$ vs. $12 \%$ at 4 years, $P=0.04$; RR $27.8,95 \%$ CI 1.13 681; Fig. 2).

\section{Secondary endpoints (long-term follow-up)}

The secondary endpoint events are summarized in Table 2. In the medical group, two patients died from
Fig. 2 Risk ratios according to treatment assignment in subgroups

\section{Stenting better}

Medical treatment better

Occlusive disease of the contralateral VA

Age $>70 y$

Sex

Stroke as index event

TIA as index event

Hypertension

Diabetes

Hypercholesterolemia

Cigarette smoking

CAD

PAD

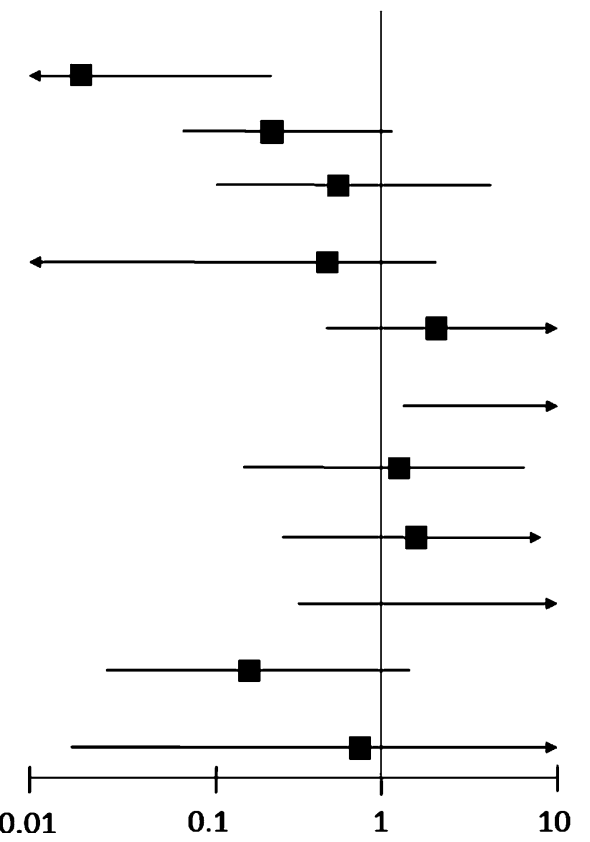


cancer 3 and 4 years after the index event, respectively. One patient suffered a hemorrhagic stroke 2 months after the index event, while taking oral anticoagulants; the same patient died from pneumonia 2 years after the index event. One patient suffered an ischemic stroke in the anterior circulation 6 years after the index event. In the stented group, an asymptomatic restenosis was diagnosed 9 months postprocedure. The patient was primary treated with a bare-metal stent; then, he underwent reintervention with a drug-eluting stent and remained asymptomatic with no further restenosis during the following 12 months.

\section{Discussion}

Patients with symptomatic severe ( $>70 \%)$ OVAS face an $11 \%$ annual risk of recurrent PCS or TIA under medical treatment. This risk is much lower $(2.5 \%)$ after VAS, though the difference is not statistically significant at the 4-year mark. Patients with occlusive disease of both vertebral arteries have a significantly lower risk of stroke/TIA recurrence after VAS compared with medical treatment. The risk of recurrent events in patients with hypertension is significantly higher in the endovascular than in the medical group. These are the main results of the present small study.
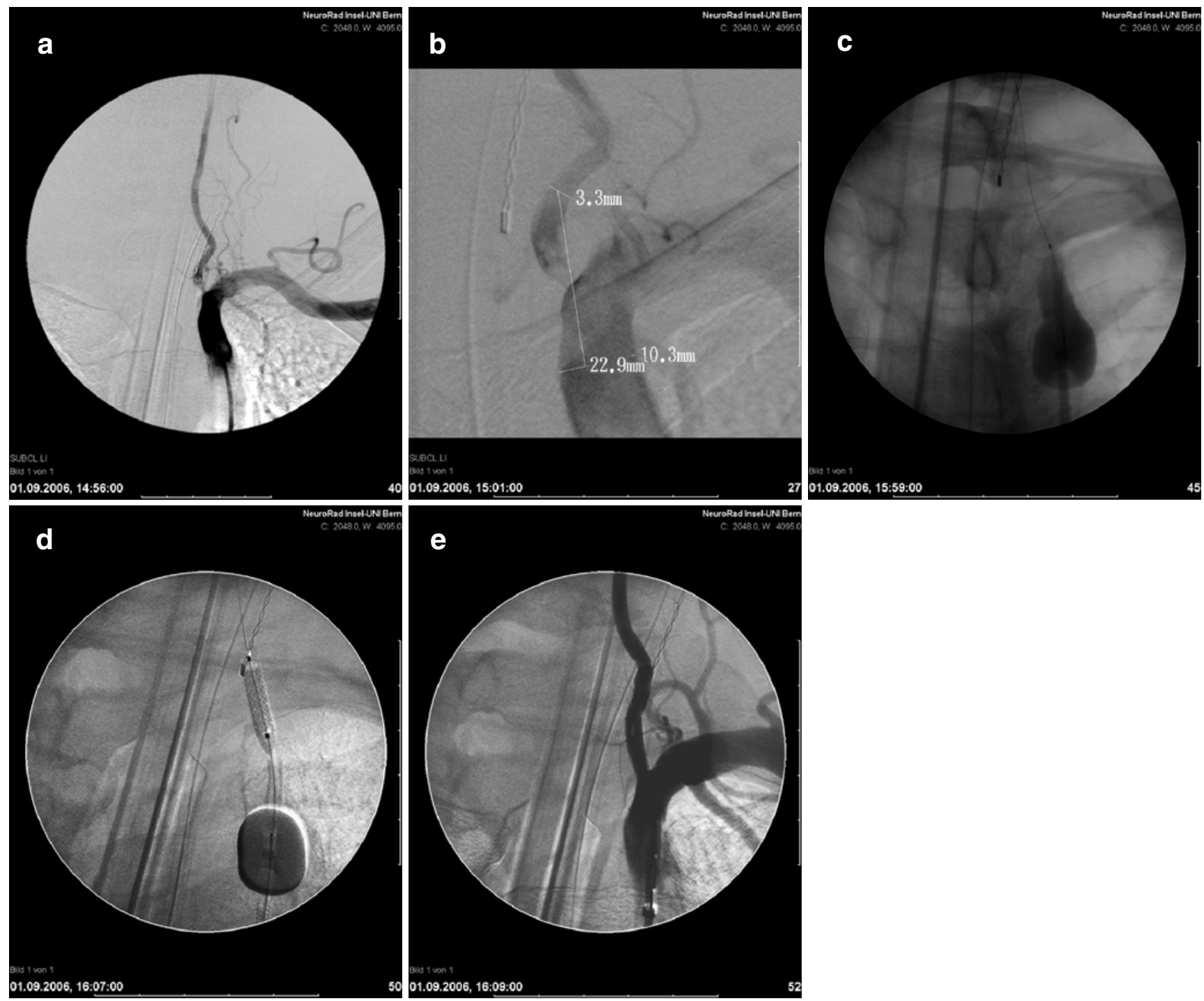

Fig. 4 Proximal protection device (Mono-MOMA). 57-year-old woman with acute vertebrobasilar symptoms. a The angiography of the left subclavian artery shows left-sided vertebral artery stenosis. b Highresolution DSA confirms VA stenosis with thrombotic material in the subclavian and vertebral artery. c Flow arrest with stagnating contrast distal from the balloon in the proximal subclavian artery. Washout of the contrast, distally from the origin of the vertebral artery, due to the iatrogenic vertebral steal from right to the left. d Stenting procedure, during proximal protection by inverted flow, in the left vertebral artery. e Remodeling of the origin of the left vertebral artery 
To date, few studies have compared medical and endovascular treatment in the secondary prevention of patients with OVAS. The only randomized study, the CAVATAS, failed to demonstrate the superiority of the endovascular over the medical treatment [7]. However, this study included only 16 patients with moderate to severe $(>50 \%)$ VA stenosis and did not consider occlusive disease of the contralateral VA artery. During the follow-up of 4.7 years, no patient in either treatment group experienced a vertebrobasilar territory stroke, but two patients experienced a TIA at the time of endovascular treatment. Three patients in each treatment arm died of myocardial infarction or carotid territory stroke, and one endovascular patient had a nonfatal carotid territory stroke. The study emphasized the importance of the global reduction of vascular risk. The annual rates of symptom recurrence were $11 \%$ and $5 \%$ in the endovascular and the medical groups, correspondingly. These figures are comparable with the annual risk of stroke/TIA recurrence observed in the present study, though in our series there is a nonsignificant trend in favor of the endovascular treatment. There was a subgroup of patients - those with a bilateral pathology of the VA - who derived a significant benefit from VAS when compared to medical treatment (Figs. 2 and 3). The hemodynamic compromise in patients with bilateral VA stenosis seems to be a major contributor to the significantly higher rate of recurrent vertebrovascular ischemia in the medical group. Surprisingly, hypertensive patients had a 28-fold increased risk of stroke/TIA recurrence after VAS than with medical treatment. However, the $95 \%$ confidence interval ranged between 1.1 and 682 , indicating that the increased risk might be a chance observation due to the skewed distribution of hypertensive patients in both groups.
Several studies have assessed the technical success and the safety of the endovascular treatment of patients with OVAS [16-20]. Typically, the endovascular treatment was associated with a high rate of technical success (up to $100 \%)$. Earlier studies performed percutaneous angioplasty without stenting [7, 14]. Later on, bare-metal and drugeluting stents have been employed [15-18]. In the present study, angioplasty with primary stenting was employed in all patients. Five patients were treated with drug-eluting stents, and five patients received bare-metal stents. The procedure was successful in all ten patients (100\%).

The major risk of endovascular treatment is dislodgement and distal embolization of plaque and thrombotic debris, which may lead to stroke. Previous studies have reported $6.4 \%$ periprocedural risk within 30 days postprocedure [21]. A recent study assessed the technical and clinical outcomes of 72 patients with ostial vertebral stenoses [22]. In 23 (32\%) asymptomatic patients, VAS was performed as a primary preventive measure. In the remaining patients, the OVAS was symptomatic. Periprocedural stroke was associated with attempted treatment of a tandem intracranial stenosis, while traditional vascular risk factors were not. The risk of the procedure likely depended on the severity of stenosis. In contrast to this study, our series includes only patients with symptomatic severe OVAS. In the VAS group, one TIA occurred 1 day postprocedure $(10 \%)$. There were no hemorrhagic strokes, strokes in the anterior circulation, MI, or reinterventions within 30 days after the index event. Our results are consistent with other published series demonstrating a low periprocedural risk of VAS.

There are currently only few studies using neuroprotection devices (NPD) for vertebral artery stenting. The feasibility of vertebral origin stenting using distal NPD was assessed in a
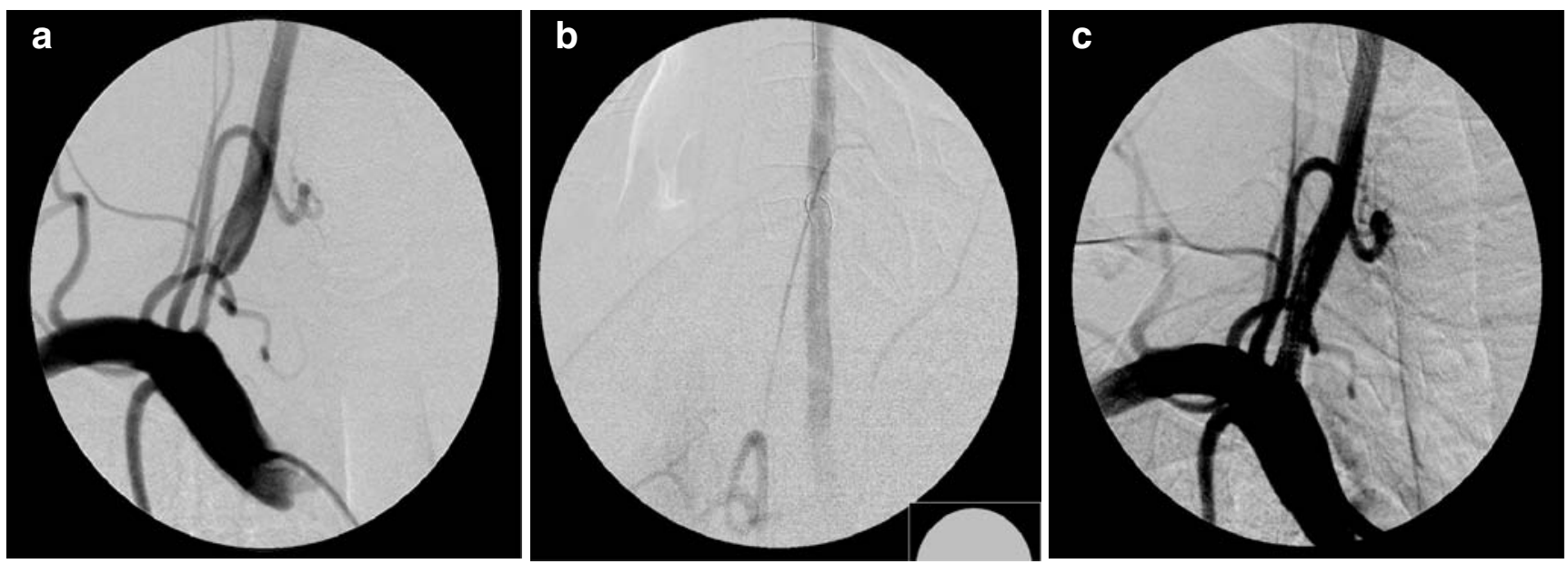

Fig. 5 Distal protection device (FilterWire). A 42-year-old man suffering from recurrent symptoms of vertebrobasilar insufficiency. a The angiography of the right subclavian artery demonstrates stenosis of the right vertebral artery. b A distal protection device (FilterWire,

Boston Scientific) in place during PTA. c A remodeling of the origin of the right vertebral artery after stent implantation (Taxus stent, Boston Scientific) 
series by Qureshi et al.[23] The authors reported no major complications within the 30-day period. The use of proximal NPD, however, seems to be confined only to cases with high-risk lesions, where distal NPD can potentially lead to device-related embolization during the passage of unstable lesion ("unprotected" lesion crossing). A double-balloon technique with simultaneous transfemoral and transbrachial approach for angioplasty of high-risk subclavian and vertebral origin stenoses has been proposed by Staikov et al. in a previous report [24]. Nevertheless, since the benefit of NPD in vertebral artery stenting is yet to be proven, protection devices were applied in our series only by exception. A distal protection and a proximal protection with flow reversal were used in one patient each with high risk of debris dislodgment (Figs. 4 and 5).

In VAS, restenosis is an important issue. In balloon angioplasty without stenting, the restenosis rates reported in the literature are very high (up to $100 \%$ at 1 year) [14]. Primary stenting reduces the restenosis rates to $10-45 \%$ $[25,26]$, though the pathophysiology and the predicting factors of restenosis are still under evaluation. Earlier studies used bare-metal stents and reported high restenosis rates (up to $67 \%$ at 6 months) [27]. More recently, drugeluting stents developed for coronary interventions have been used to treat cerebrovascular lesions. The reported restenosis rates were moderate to low, though the follow-up intervals were relatively short ( $7 \%$ at 4 months [28], $0 \%$ at 11 months [29], $<5 \%$ at 14 months [30]). In our series, one asymptomatic restenosis occurred during the 4-year followup. Notably, the only restenosis occurred in a patient treated with a bare-metal stent. No further restenosis was observed during a follow-up of 12 months, after treatment with a DES of the in-stent stenosis in the bare-metal stent.

Our study has several limitations. First, treatment assignment was not random, and comparisons between medical and endovascular treatment should be interpreted with caution. For example, medically treated patients were significantly older, which may have contributed to the higher rate of stroke/TIA recurrence. Furthermore, bilateral VA stenosis was more frequent in the stented group. Second, the small sample size precluded subgroup analyses. For instance, it remains unclear whether clopidogrel is superior to aspirin in the prevention of subsequent ischemic stroke or TIA in the vertebrobasilar territory. Also, the role of hypertension as a predictor of recurrent events seems to be a chance observation due to the skewed distribution of hypertensive patients in both groups.

In conclusion, VAS can be safely performed in patients with symptomatic severe OVAS. The long-term benefit however appears to be confined to patients with bilateral but not to those with unilateral VA disease. Randomized controlled trials are needed to define the optimum management of patients with severe stenosis of the vertebral artery.
Acknowledgements The authors would like to thank Mr. Pietro Ballinari and Mr. Martin Zbinden for their statistical advice.

Conflict of interest statement We declare that we have no conflict of interest.

\section{References}

1. Bamford J, Sandercock P, Dennis M, Burn J, Warlow C (1991) Classification and natural history of clinically identifiable subtypes of cerebral infarction. Lancet 337(8756):1521-1526

2. Bogousslavsky J, Van Melle G, Regli F (1988) The Lausanne stroke registry: analysis of 1,000 consecutive patients with first stroke. Stroke 19(9):1083-1092

3. Hass WK, Fields WS, North RR, Kircheff II, Chase NE, Bauer RB (1968) Joint study of extracranial arterial occlusion. II. Arteriography, techniques, sites, and complications. JAMA 203 (11):961-968

4. Wityk RJ, Chang HM, Rosengart A, Han WC, DeWitt LD, Pessin MS, Caplan LR (1998) Proximal extracranial vertebral artery disease in the New England medical center posterior circulation registry. Arch Neurol 55(4):470-478

5. Castaigne P, Lhermitte F, Gautier JC, Escourolle R, Derouesné C, Der Agopian P, Popa C (1973) Arterial occlusions in the vertebrobasilar system: a study of 44 patients with post-mortem data. Brain 96:133-154

6. Caplan LR, Tettenborn B (1992) Vertebrobasilar occlusive disease: review of selected aspects. Cerebrovasc Dis 2:256-265

7. Coward LJ, McCabe DJ, Ederle J, Featherstone RL, Clifton A, Brown MM (2007) CAVATAS investigators. Long-term outcome after angioplasty and stenting for symptomatic vertebral artery stenosis compared with medical treatment in the carotid and vertebral artery transluminal angioplasty study (CAVATAS): a randomized trial. Stroke 38(5):1526-1530

8. Compter A, van der Worp H, Schonewille W, Vos J, Algra A, Lo T, Mali W, Moll F, Kappelle Lj (2008) VAST: Vertebral Artery Stenting Trial. Protocol for a randomised safety and feasibility trial. Trials 9:65

9. Brott T, Adams HP Jr, Olinger CP, Marler JR, Barsan WG, Biller J, Spilker J, Holleran R, Eberle R, Hertzberg V, Roorick M, Moomaw CJ, Walker M (1989) Measurements of acute cerebral infarction: a clinical examination scale. Stroke 20:846-870

10. Adams HP, Bendixen BH, Kappelle LJ, Biller J, Love BB, Gordon DL, Marsh EE III (1993) Classification of subtype of acute ischemic stroke. Definitions for use in a multicenter clinical trial. TOAST. Trial of Org 10172 in Acute Stroke Treatment. Stroke 24:35-41

11. Ackerstaff RG, Grosveld WJ, Eikelboom BC, Ludwig JW (1988) Ultrasonic duplex scanning of the prevertebral segment of the vertebral artery in patients with cerebral atherosclerosis. Eur J Vasc Surg 2(6):387-393

12. North American Symptomatic Carotid Endarterectomy Trial (1991) Methods, patient characteristics, and progress. Stroke 22 (6):711-720

13. Nedeltchev K, Remonda L, Do DD, Brekenfeld C, Ozdoba C, Arnold M, Mattle HP, Schroth G (2004) Acute stenting and thromboaspiration in basilar artery occlusions due to embolism from the dominating vertebral artery. Neuroradiology 46(8):686-691

14. Randoux B, Marro B, Koskas F, Chiras J, Dormont D, Marsault (2003) Proximal great vessels of aortic arch: comparison of threedimensional gadolinium-enhanced MR angiography and digital subtraction angiography. Radiology 229:697-702

15. De Bray JM, Pasco A, Tranquart F, Papon X, Alecu C, Giraudeau B, Dubas F, Emile J (2001) Accuracy of color-Doppler in the 
quantification of proximal vertebral artery stenoses. Cerebrovasc Dis 11(4):335-340

16. Cloud GC, Crawley F, Clifton A, McCabe DJ, Brown MM, Markus HS (2003) Vertebral artery origin angioplasty and primary stenting: safety and restenosis rates in a prospective series. J Neurol Neurosurg Psychiatry 74:586-590

17. Mukherjee D, Roffi M, Kapadia SR, Bhatt DL, Bajzer C, Ziada KM, Kalahasti V, Hughes K, Yadav JS (2001) Percutaneous intervention for symptomatic vertebral artery stenosis using coronary stents. J Invasive Cardiol 13:363-366

18. Piotin M, Spelle L, Martin J-B, Weill A, Rancurel G, Ross IB, Rüfenacht DA, Chiras J (2000) Percutaneous transluminal angioplasty and stenting of the proximal vertebral artery for symptomatic stenosis. AJNR Am J Neuroradiol 21:727-731

19. Storey GS, Marks MP, Dake M, Norbash AM, Steinberg GK (1996) Vertebral artery stenting following percutaneous transluminal angioplasty. J Neurosurg 84:883-887

20. Lin YH, Juang JM, Jeng JS, Yip PK, Kao HL (2004) Symptomatic ostial vertebral artery stenosis treated with tubular coronary stents: clinical results and restenosis analysis. J Endovasc Ther 11(6):719-726

21. Coward LJ, Featherstone RL, Brown MM (2005) Percutaneous transluminal angioplasty and stenting for vertebral artery stenosis. Cochrane Database Syst Rev 18(2):CD000516

22. Taylor RA, Siddiq F, Memon MZ, Qureshi AI, Vazquez G, Hayakawa M, Chaloupka JC (2009) Vertebral artery ostial stent placement for atherosclerotic stenosis in 72 consecutive patients: clinical outcomes and follow-up results. Neuroradiology 51(8):531-539

23. Qureshi AI, Kirmani JF, Harris-Lane P, Divani AA, Ahmed S, Ebrihimi A, Al Kawi A, Janjua N (2006) Vertebral artery origin stent placement with distal protection: technical and clinical results. AJNR Am J Neuroradiol 27:1140-1145

24. Staikov IN, Do DD, Remonda L, Mattle H, Baumgartner R, Schroth G (1999) The site of atheromatosis in the subclavian and vertebral arteries and its implication for angioplasty. Neuroradiology 41:537-542

25. Albuquerque FC, Fiorella D, Han P, Spetzler RF, McDougall CG (2003) A reappraisal of angioplasty and stenting for the treatment of vertebral origin stenosis. Neurosurgery 53:607-614

26. Chastain HD 2nd, Campbell MS, Iyer S, Roubin GS, Vitek J, Mathur A, Al-Mubarak NA, Terry JB, Yates V, Kretzer K, Alred D, Gomez CR (1999) Extracranial vertebral artery stent placement: in-hospital and follow-up results. J Neurosurg 91(4):547-552

27. SSYLVIA Study Investigators (2004) Stenting of Symptomatic Atherosclerotic Lesions in the Vertebral or Intracranial Arteries (SSYLVIA): study results. Stroke 35(6):1388-1392

28. Gupta R, Al-Ali F, Thomas AJ, Horowitz MB, Barrow T, Vora NA, Uchino K, Hammer MD, Wechsler LR, Jovin TG (2006) Safety, feasibility, and short-term follow-up of drug-eluting stent placement in the intracranial and extracranial circulation. Stroke 37(10):2562-2566

29. Abou-Chebl A, Bashir Q, Yadav JS (2005) Drug-eluting stents for the treatment of intracranial atherosclerosis: initial experience and midterm angiographic follow-up. Stroke 36(12):e165e168

30. Qureshi AI, Kirmani JF, Hussein HM, Harris-Lane P, Divani AA, Suri MF, Janjua N, Alkawi A (2006) Early and intermediate-term outcomes with drug-eluting stents in high-risk patients with symptomatic intracranial stenosis. Neurosurgery 59(5):10441051 